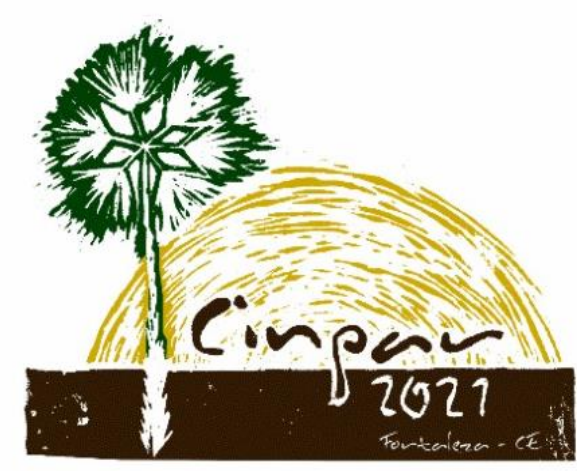

XVII Congresso Internacional sobre Patologia e

Reabilitação das Construções

XVII Congreso Internacional sobre Patología y Rehabilitación de las Construcciones

XVII International Conference on Pathology and Constructions Rehabilitation

FORTALEZA (Brasil), 3 a 5 de junho de 2021

https://doi.org/10.4322/CINPAR.2021.158

\title{
Análise das manifestações patológicas em uma edificação histórica: A capela de Santa Luzia em Carnaubais/RN
}

\section{Analysis of pathological manifestations in a historic building: The chapel of Santa Luzia in Carnaubais/RN}

\author{
Antunes França EDUARDO ${ }^{1}$, Juliana Estefanie da Silva SANTOS ${ }^{2}$ \\ ${ }^{1}$ Universidade Federal do Rio Grande do Norte, Natal, Brasil, antunesfilho1@hotmail.com \\ ${ }^{2}$ Universidade Federal Rural do Semi-Árido, Angicos, Brasil, juliana_estephany@hotmail.com
}

\begin{abstract}
Resumo: A capela de Santa Luzia é uma edificação antiga que tem um importante valor histórico e cultural para o povo de Carnaubais e da região, pois é utilizada como templo de oração sendo a representação e um símbolo da fé centenária dos seus devotos. Sendo assim, é de suma importância conservar a estrutura dessa edificação. Dessa maneira, este trabalho teve como objetivo principal identificar as manifestações patológicas e as causas da sua ocorrência e assim propor um plano de manutenção corretiva dessas manifestações existentes na edificação da capela de Santa Luzia e fazer com que esse patrimônio seja conservado. Para isso, foi realizado um levantamento das principais manifestações patológicas presentes na edificação, por meio de visitas in loco e registros fotográficos. As manifestações patológicas presentes na edificação são: bolor, destacamento da pintura, eflorescência, desprendimento de revestimento argamassado, cupim na madeira e biqueiras na cobertura.
\end{abstract}

Palavras-chave: Manifestações patológicas. Edificações históricas. Plano de manutenção.

\section{Introdução}

O processo de deterioração nas edificações ocorre devido à degradação provocada por alguns fatores como falhas nas etapas construtivas (planejamento, projeto, execução, materiais impróprios ou incompatíveis, utilização e manutenção) e intempéries. Havendo assim, a necessidade de manutenções periódicas para mitigar a deterioração precoce da obra.

O estudo das manifestações patológicas é de suma importância para a conservação das edificações. De acordo com Lira (2015), as edificações, em geral, estão suscetíveis ao surgimento dessas manifestações e quando a construção apresenta esse fenômeno, passa a ter seu desempenho ameaçado, sendo necessário um diagnóstico para que se possa realizar os reparos e intervir na degradação do edifício. Em obras históricas, isso é muito importante, pois é preciso preservar o patrimônio histórico.

De acordo com o Instituto do Patrimônio Histórico e Artístico Nacional (2014), o patrimônio histórico pode ser definido como um bem que apresenta significado e expressa importância para a sociedade, pois conservam a história de sociedades passadas.

A Capela de Santa Luzia é um prédio histórico construída em 1917, localizada no município de Carnaubais/RN. Sua estrutura foi prejudicada pelas fortes precipitações pluviométricas na região, tendo ocorrido sua demolição e reconstrução em 1924.

Essa pesquisa tem como objetivo geral identificar as manifestações patológicas existentes na Capela de Santa Luzia. Como objetivos específicos tem-se: elaborar um plano de manutenção e fazer um cronograma das atividades necessárias para recuperação da edificação. 


\section{Metodologia}

O presente trabalho caracteriza-se como um estudo de caso das manifestações patológicas presentes na capela de Santa Luzia localizada em Carnaubais/RN.

Para a identificação das manifestações patológicas foi realizada uma coleta de dados através de vistorias feitas na edificação onde procedeu-se a inspeção visual e registros fotográficos. A partir disso, foi feita a identificação das manifestações patológicas presentes na edificação em estudo indicando o tipo e a sua causa com base nas normas brasileiras vigentes e literatura consagrada. Em seguida, foi elaborado e proposto um plano de manutenção e cronograma das atividades necessárias para recuperação da edificação.

\section{Resultados e discussão}

Nesse tópico será discutido as manifestações encontradas na edificação e as suas causas. Em seguida, será proposto um plano de manutenção para a conservação desse patrimônio histórico.

\subsection{Manifestações presentes na edificação}

Uma das principais manifestações encontradas na edificação é o bolor que foi destacado na Figura 1.

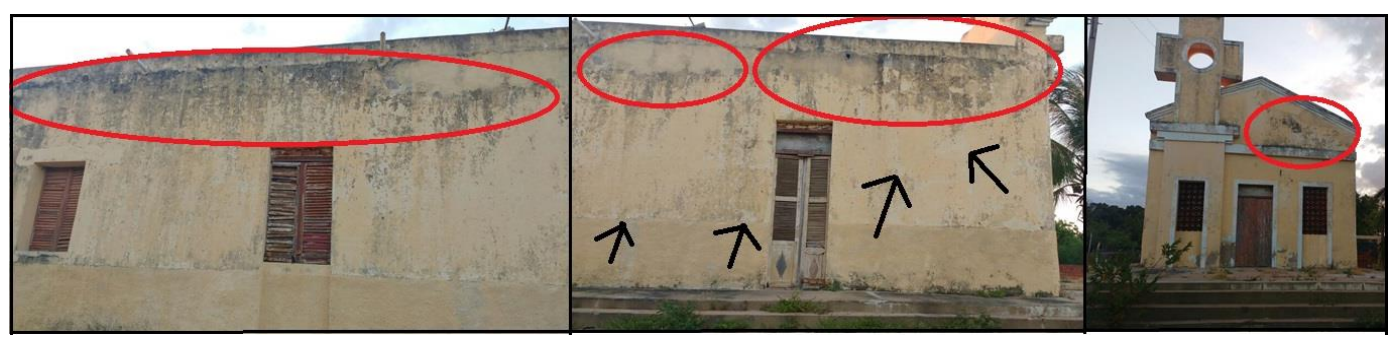

Figura 1 - Presença de bolor na parte superior das fachadas lateral.

O bolor é o aparecimento de fungos que geralmente são da cor preta ou esverdeado em locais de pouca luminosidade e ventilação e/ou locais em que a umidade entre em contado com a edificação. De acordo com Sadika (2013), essa umidade pode ser proveniente do excesso da mesma no ar devido ao clima, a falhas construtivas ou à umidade interna da parede adquirida pela capilaridade, ou mesmo por erro ou falta de impermeabilização.

Outras manifestações patológicas presentes na fachada é o destacamento da pintura e a eflorescência como é mostrado na Figura 2.

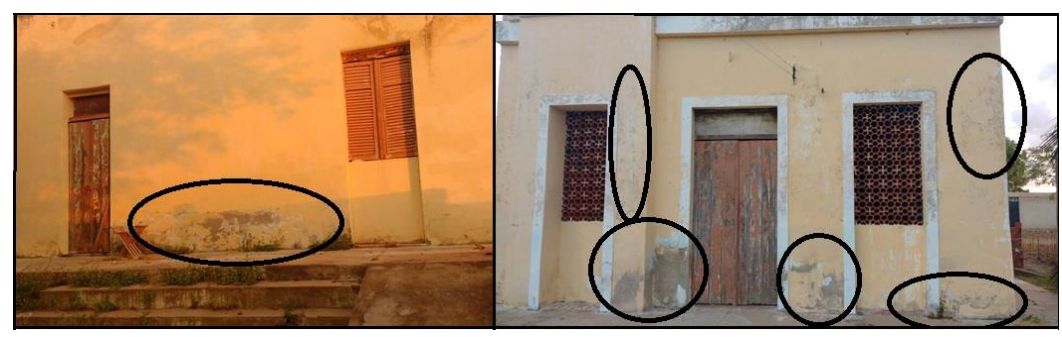

Figura 2 - Destacamento da pinturana fachada lateral e na frontal.

Essas manifestações patológicas também estão presentes na parte interna da edificação como é indicada na Figura 3. 


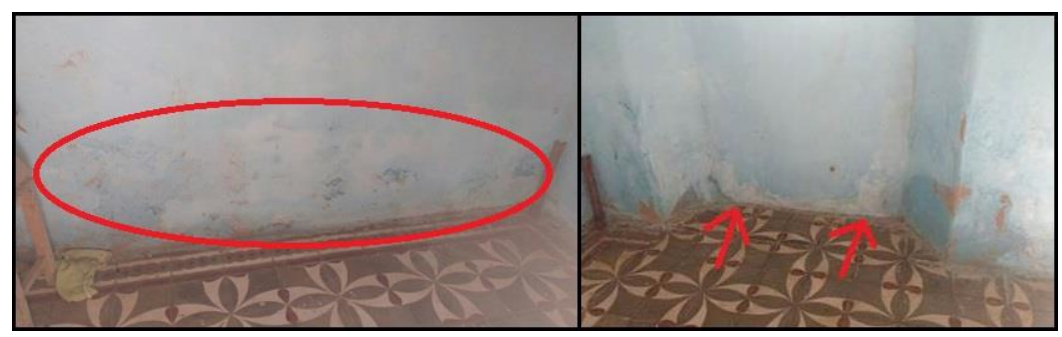

Figura 3 - Destacamento da pintura e eflorescência em parede interna da edificação.

De acordo com Vitório (2003), a eflorescência é o depósito de sais acumulado sobre a superfície das alvenarias, de composição e aspecto variáveis. Para Segat (2005), esse fenômeno resulta da migração para a superfície dos sais solúveis presentes no cimento, nos tijolos, na argamassa, no concreto ou na areia, utilizada para promover a trabalhabilidade e hidratação do cimento. Esses sais chegam a superfície através do seu agente transportador que é a água presente no ambiente.

O bolor, a eflorescência e o destacamento da pintura mostrados acima são causados pela umidade presente no solo onde está localizada a edificação. Pois, tem leito de rio que passa pela região e quando o rio está em cheia abrange toda a região próxima à igreja. Sendo assim, o solo é muito úmido e essa umidade atinge a edificação por ascensão capilar da água presente no solo.

Na cobertura foi observada a incidência de cupim nas linhas que sustentam o telhado como mostra a Figura 4.

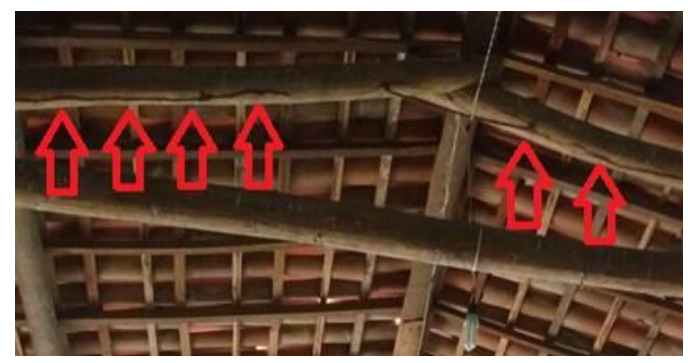

Figura 4 - Presença de cupim nas linhas de sustentação do telhado.

Esse cupim é causado devido a ocorrência dessas linhas com a umidade e essa umidade vem das chuvas e do ar e entram em contato com as linhas através das biqueiras existentes no telhado como é mostrado na Figura 5 .

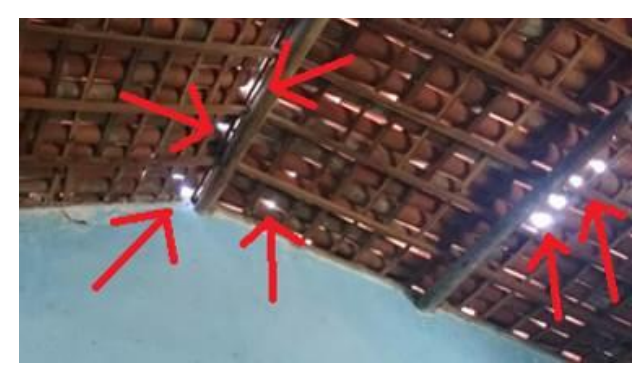

Figura 5 - Ocorrência de biqueira no telhado.

As biqueiras mostradas na Figura 5 são ocasionados pelo afastamento das telhas pela ocorrência de ventos fortes na região e devido a cobertura não ter um agerol que possibilita um encaixe melhor das telhas faz com que elas fastem com facilidade.

Outra manifestação presente na edificação é o destacamento de revestimento, como mostra a Figura 6. 


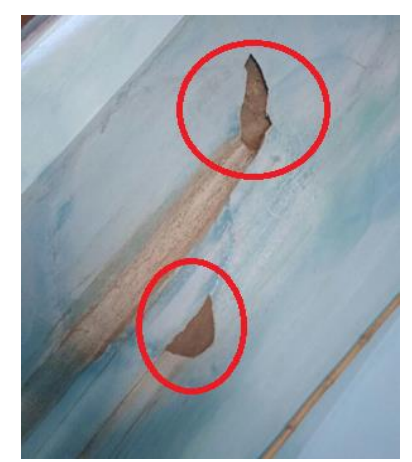

Figura 6 - Destacamento de revestimento.

Essa manifestação consiste na remoção do revestimento da alvenaria causado por algum fator que de acordo com loshimoto (1994), podem ser: algum tipo de movimentação na estrutura; deficiência no material utilizado; falta de aderência que pode ter diversas causas como o excesso de materiais pulverulentos; ação de intemperes e expansões dos materiais. Nesse caso foi causado devido ao excesso de materiais pulverulentos na argamassa e a umidade presente na edificação.

\subsection{Plano de manutenção}

Neste item será proposto um programa de manutenção corretivo do prédio da capela de Santa Luzia, com o objetivo de aumentar a vida útil da edificação e conservar esse patrimônio histórico cultural da cidade de Carnaubais/RN.

$\mathrm{Na}$ cobertura, tem-se que substituir as telhas quebradas e das linhas que estão com cupim. Para a substituição das linhas, de acordo com Pastina Filho (2005), a substituição das linhas deve ser feita por outras linhas de mesma dimensão e se possível, madeira com as mesmas características da original. Para o caso da edificação estudada é melhor fazer a substituição de todas as linhas, pois a madeira nunca foi mudada em nenhuma reforma.

Para a correção do desprendimento da pintura é necessário fazer o lixamento das paredes e aplicar novas demão de tinta. Para prevenir o aparecimento dessa manifestação é necessário a realização de reparos na pintura durante um intervalo de tempo menor do que vem acontecendo, como por exemplo a cada ano.

A eflorescência pode ser removida de acordo com a NBR 7200 (1998) através da escovação da superfície com escova de cerdas de aço e proceder à limpeza com solução de ácido muriático.

O destacamento do revestimento deve-se cortar a área do revestimento com delimitações de áreas retangular, e aplicar um novo revestimento.

Para remover bolor e fungos segundo a NBR 7200 (1998) pode-se escovar a superfície com escova de cerdas duras com solução de fosfato trissódico (30 g Na3PO4 em $1 \mathrm{~L}$ de água) ou com solução de hipoclorito de sódio (4\% a $6 \%$ de cloro ativo) e enxaguar com água limpa em abundância.

No Quadro 1, tem-se um cronograma da execução desses reparos. Pode-se verificar através dessa tabela que todos os reparos podem ser realizados em um tempo de 3 semanas.

Quadro 1 - Cronograma de execução dos reparos do plano de manutenção.

\begin{tabular}{|c|c|}
\hline Semana & Atividade Realizada \\
\hline I & Reparos na cobertura \\
\hline II & Eliminação de bolor e eflorescência \\
\hline III & $\begin{array}{c}\text { Reparos no destacamento de revestimento e na } \\
\text { pintura }\end{array}$ \\
\hline
\end{tabular}




\section{Conclusões}

Através do estudo das manifestações patológicas na capela de Santa Luiza em Carnaubais foi possível concluir que:

- A edificação tem grande incidência de bolor nas fachadas da edificação, destacamento da pintura em todas as paredes e a degradação da madeira e das telhas.

- As manifestações encontradas ocorreram pela falta de manutenção da edificação, pois faz mais de 10 anos que não é feito nenhum tipo de reparo ou reforma nesta edificação.

- A partir do plano de manutenção proposto no trabalho a paróquia de Carnaubais pode adotar esse plano para que se possa conservar a edificação que representa parte da história do povo de Carnaubais.

\section{Referências Bibliográficas}

PASTILHA FILHO, J. L. Manual de conservação de telhados: Restaurando o telhado. Brasília: IPHAN;1ạ edição, 2005, p. $35-43$.

IPHAN. Patrimonio Cultural. Disponivel em: <http://portal.iphan.gov.br/pagina/detalhes/218>. Acesso em: 01 de agosto de 2017.

LIRA, Ornella Almeida Lacerda. Estudo de manifestações patológicas do Centro Comercial Teonila Amélia Cruz de Araújo (Mercado Central) na cidade de Angicos - RN. 2015. 58f. Monografia (Bacharel em Engenharia Civil) - Universidade Federal Rural do Semi-Árido, Angicos, 2015.

SADIKA, Jasmim Mohamed Hussein. Levantamento de patologias causadas por infiltrações devido à falha ou ausência de impermeabilização em construções residenciais na cidade de Campo Mourão - PR. 2013. 54f. Monografia (Bacharel em Engenharia Civil) - Universidade Tecnológica Federal do Paraná, Campo Mourão, 2013.

SEGAT, G. T. Manifestações patológicas observadas em revestimentos de argamassa: estudo de caso em conjunto habitacional popular na cidade de Caxias do Sul. 2005. 166f. Dissertação (mestrado profissional) - Universidade Federal do Rio Grande do Sul, Porto Alegre, 2005.

VITÓRIO, Afonso. Fundamentos das estruturas nas perícias de engenharia. 1. ed. Recife: IBAPE, 2003.

IOSHIMOTO, Eduardo. Incidência de Manifestações Patológicas em Edificações Habitacionais. São Paulo: IPT, 1994.

ASSOCIAÇÃO BRASILEIRA DE NORMAS TÉCNICAS. Execução de revestimento de paredes e tetos de argamassas inorgânicas - Procedimento: NBR 7200, Rio de Janeiro, 1998. 13 p. 